\title{
RESEARCH
}

Open Access

\section{The SNPs rs429358 and rs7412 of APOE gene are association with cerebral infarction but not SNPs rs2306283 and rs4149056 of SLCO1B1 gene in southern Chinese Hakka population}

Heming $W u^{1,2,3,4 \dagger}$, Qingyan Huang ${ }^{1,2,3,4+}$, Zhikang $Y u^{1,2,3,4}$, Hailing $W u^{1,2,3,4}$ and Zhixiong Zhong ${ }^{1,2,3,4,5^{*}}$ (D)

\section{Abstract}

Background: Apolipoprotein E (ApoE) and solute carrier organic anion transporter family member 1B1 (SLCO1B1) regulate lipid metabolism. However, the relationship between genetic polymorphisms of APOE and SLCO1B1 and cerebral infarction $(\mathrm{Cl})$ remains unclear.

Methods: A total of $938 \mathrm{Cl}$ patients and 1028 control participants were included in the study. The rs429358 and rs7412 single nucleotide polymorphisms (SNPs) in the APOE gene and rs2306283 and rs4149056 SNPs in the SLCO1B1 gene were analyzed by fluorescence polymerase chain reaction (PCR).

(Continued on next page)

\footnotetext{
*Correspondence: zhongzhixiong01@126.com; zhongzhixiong@mzrmyy.com

${ }^{\dagger}$ Heming Wu and Qingyan Huang contributed equally to this work.

${ }^{1}$ Center for Precision Medicine, Meizhou People's Hospital (Huangtang

Hospital), Meizhou Academy of Medical Sciences, Meizhou Hospital Affiliated

to Sun Yat-sen University, Meizhou, P. R. China

${ }^{2}$ Guangdong Provincial Key Laboratory of Precision Medicine and Clinical

Translational Research of Hakka Population, Meizhou People's Hospital

(Huangtang Hospital), Meizhou Academy of Medical Sciences, Meizhou

Hospital Affiliated to Sun Yat-sen University, Meizhou, P. R. China

Full list of author information is available at the end of the article
}

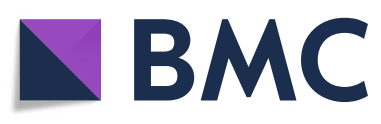

(- The Author(s). 2020 Open Access This article is licensed under a Creative Commons Attribution 4.0 International License, which permits use, sharing, adaptation, distribution and reproduction in any medium or format, as long as you give appropriate credit to the original author(s) and the source, provide a link to the Creative Commons licence, and indicate if changes were made. The images or other third party material in this article are included in the article's Creative Commons licence, unless indicated otherwise in a credit line to the material. If material is not included in the article's Creative Commons licence and your intended use is not permitted by statutory regulation or exceeds the permitted use, you will need to obtain permission directly from the copyright holder. To view a copy of this licence, visit http://creativecommons.org/licenses/by/4.0/ The Creative Commons Public Domain Dedication waiver (http://creativecommons.org/publicdomain/zero/1.0/) applies to the data made available in this article, unless otherwise stated in a credit line to the data. 
(Continued from previous page)

Results: The genotype $\varepsilon 3 / \varepsilon 3$ was the most common APOE genotype, with $\varepsilon 3$ being the allele with the highest frequency, followed by $\varepsilon 4$ and $\varepsilon 2$. Statistically significant differences of genotype $\varepsilon 2 / \varepsilon 2\left(X^{2}=3.866, P=0.049\right), \varepsilon 2 / \varepsilon 3$ $\left(x^{2}=20.030, P<0.001\right), \varepsilon 3 / \varepsilon 4\left(X^{2}=16.960, P<0.001\right)$, and $\varepsilon 4 / \varepsilon 4\left(X^{2}=4.786, P=0.029\right)$ between $C l$ patients and controls were detected. The SLCO1B1 genotype ${ }^{* 1} 1 \mathrm{~b} /{ }^{*} 1 \mathrm{~b}$ and haplotype ${ }^{*} 1 \mathrm{~b}$ showed the highest frequency in the study sample. There was no statistically significant difference in the frequencies of SLCO1B1 genotypes and haplotypes among CI patients comparing with controls. Moreover, $\varepsilon 4$ carriers had significantly higher low-density lipoprotein-cholesterol (LDL-C) and apolipoprotein B (Apo-B) and lower apolipoprotein A1 (Apo-A1)/Apo-B levels than $\varepsilon 2$ and $\varepsilon 3$ carriers, but $\varepsilon 2$ carriers showed lower LDL-C and Apo-B and higher Apo-A1/Apo-B than $\varepsilon 3$ and $\varepsilon 4$ carriers. Further, logistic regression analysis revealed that high $L D L-C$, high $A p o B$, smoking, hypertension and the $\varepsilon 4$ allele were risks for the presence of $\mathrm{Cl}$.

Conclusions: This study indicated that the APOE SNPs rs429358 and rs7412 may be associated with susceptibility to cerebral infarction in southern Chinese Hakka population.

Keywords: Apolipoprotein E, Solute carrier organic anion transporter family member 1B1, Gene polymorphism, Cerebral infarction, Relationship, Hakka

\section{Introduction}

Ischemic cerebral infarction (CI) refers to ischemic necrosis or softener of local brain tissue caused by cerebral blood circulation disorder, ischemia and hypoxia, with appearance of corresponding neurological defects. Clinically, patients often have vertigo, diplopia, gait instability, limb shaking and other manifestations. CI is a major disease that seriously endangers human health, accounting for approximately $70 \%$ of stroke [1]. The risk of CI may vary according to the presence of various genetic and environmental factors. In addition, the relationship between the functional variation of multiple gene in different ethnic groups and CI risk has been studied, including the polymorphisms of interleukin- 6 gene [2], $\beta$ fibrinogen gene [3], PON1 hypermethylation and PON3 hypomethylation [4], 5-lipoxygenase-activating protein gene association (ALOX5AP) [5], the cytochrome P450 1A1 (CYP1A1) gene [6], the human scavenger receptor class B type I (SR-BI) gene [7], genes associated with lipid metabolism $[8,9]$, and others [10]. In general, it is important for both risk prediction and prevention of CI by identifying genetic risk.

Apolipoprotein E (ApoE), a polymorphic protein that is mainly synthesized by the liver, can bind with chylomicron, high-density lipoprotein-cholesterol (HDL-C), low-density lipoprotein-cholesterol (LDL-C), and very low-density lipoprotein-cholesterol (VLDL-C) to participate in the transformation and metabolism of lipoprotein. ApoE plays an important role in regulating lipid metabolism by regulating the bind of these lipoproteins to specific receptors. ApoE is encoded by the $A P O E$ gene (OMIM 107741), which is located on chromosome 19. There are two common singlenucleotide polymorphisms (SNPs) of the APOE gene: 388 $\mathrm{T}>\mathrm{C}(\mathrm{rs} 429358)$ and $526 \mathrm{C}>\mathrm{T}$ (rs7412). Three haplotypes (ع2(388 T-526 T), $\varepsilon 3(388 \mathrm{~T}-526 \mathrm{C}), \varepsilon 4(388 \mathrm{C}-526 \mathrm{C}))$ and six genotypes $(\varepsilon 2 / \varepsilon 2, \varepsilon 2 / \varepsilon 3, \varepsilon 2 / \varepsilon 4, \varepsilon 3 / \varepsilon 3, \varepsilon 3 / \varepsilon 4, \varepsilon 4 / \varepsilon 4)$ can be formed by these SNPs [11]. Compared with $\varepsilon 3$ homozygotes, patients with the $\varepsilon 2$ allele have lower circulating total cholesterol (TC) levels and higher triglyceride levels, whereas those who carry the $\varepsilon 4$ allele appear to have higher plasma levels of TC and LDL-C [12].

Organic anion transporter family member 1B1 (OATP1B1, also known as solute carrier organic anion transporter family member 1B1 (SLCO1B1)) is a type of intake transporter with specific expression in liver and is responsible for the transport of endogenous and exogenous substances. OATP1B1 is encoded by the SLCO1B1 gene (OMIM 604843), which is located on chromosome $12 \mathrm{p} 12.1$ and is approximately $11 \mathrm{~kb}$ in length. The two common SNPs in the SLCO1B1 gene are 388A $>$ G (rs2306283) and $521 \mathrm{~T}>\mathrm{C}(\mathrm{rs} 4149056)$ [13, 14]. These two SNPs can be combined to produce four different haplotypes: *1a (388A-521 T), *1b (388G-521 T), *5 (388A-521C) and *15 (388G-521C) [15-17]. Most studies to date on SLCO1B1 have focused on the effect of $S L C O 1 B 1$ polymorphisms on the pharmacokinetics, efficacy and side effects of oral hypoglycemic agents, statins, and antitumor agents $[18,19]$.

However, there are few studies on the correlation between SLCO1B1 polymorphisms and CI. Although some studies in China and elsewhere have used the $A P O E$ gene as a candidate gene to analyze cardiovascular and cerebrovascular diseases, results in different regions and populations may be inconsistent. In the present study, SLCO1B1 and APOE allele/genotype frequencies and the correlation between $S L C O 1 B 1$ and $A P O E$ polymorphisms and CI were analyzed.

\section{Materials and methods Population samples}

A total of 1966 individuals were recruited from the inpatients of Meizhou People's Hospital (Huangtang 
Hospital), Guangdong province, China, between September 2016 and December 2018; the sample consisted of 938 ischemic cerebral infarction patients and 1028 individuals with non-cerebral infarction as controls. CI patients' diagnoses were verified by neurologists according to clinical symptoms and computed tomography (CT)/ magnetic resonance imaging (MRI). Patients with transient ischemic attacks, cardiogenic cerebral infarctions, cerebral hemorrhage, or malignant tumors were excluded. Information recorded included age, sex, and cerebrovascular disease risk factors. A flow diagram of the study population recruitment process is illustrated in Fig. 1. Patients were recruited after being diagnosed with $\mathrm{CI}$ and with the consent of the patients or their family members. All control subjects were randomly selected from the Physical Examination Center of the Meizhou People's Hospital during the same period. This retrospective case control study was approved by the Human Ethics Committees of Meizhou People's Hospital (Clearance No.: 2016-A-29).

\section{Plasma lipid measurements}

On the second day of admission, approximately $3 \mathrm{ml}$ of blood was taken from each subject, and plasma was isolated and tested promptly or store at $-80^{\circ} \mathrm{C}$ for further analysis. Serum samples were evaluated using the Olympus AU5400 system (Olympus Corporation, Tokyo, Japan) for TC, triglyceride (TG), LDL-C, HDL-C, apolipoprotein B (Apo-B) and apolipoprotein A1 (Apo-A1). TC, TG,
LDL-C, HDL-C, Apo-A1/Apo-B analyses were carried out using cholesterol esterase/peroxidase (CHOD/PAP) enzymatic method, Glycerophosphate oxidase/peroxidase (GPO-PAP) enzymatic method, direct surfactant removal method, direct immunoinhibition method, and immunoturbidimetry method, respectively.

\section{DNA extraction and genotyping assay}

Genomic DNA was extracted from whole blood in EDTA using a QIAamp DNA Blood Mini Kit (Qiagen GmbH, North Rhine-Westphalia, Germany) according to the protocol provided. The DNA concentration was measured using a Nanodrop $2000^{\text {max }}$ Spectrophotometer (ThermoFisher Scientific, Massachusetts, USA). TaqMan probe fluorescent PCR was used for SLCO1B1 and APOE genotyping, in which different primers and probes combinations were designed for different SNP polymorphisms of the $S L C O 1 B 1$ and $A P O E$ genes, and gene polymorphisms at different loci were detected through different channels in the reaction system. Polymerase chain reaction (PCR) was used to amplify the target fragments $\left(\left(\right.\right.$ step $1: 37^{\circ} \mathrm{C}$ for $10 \mathrm{~min}$; step 2: $95^{\circ} \mathrm{C}$ for $5 \mathrm{~min}$; step 3 (amplification of 40 cycles): $95^{\circ} \mathrm{C}$ for $15 \mathrm{~s}$ and $60^{\circ} \mathrm{C}$ for $\left.1 \mathrm{~min}\right)$ ). The fluorescence signals, including FAM (SLCO1B1*1b 388A, SLCO1B1*5521 T, ApoE2 526C, ApoE4 $388 \mathrm{~T}$ ), VIC (SLCO1B1*1b 388G, SLCO1B1*5521C, ApoE2 $526 \mathrm{~T}$, ApoE4 388C) and ROX (internal standard) (Youzhiyou Medical Technology Co.,Ltd., Hubei, China) were collected using a Roche LightCycler 480 II.

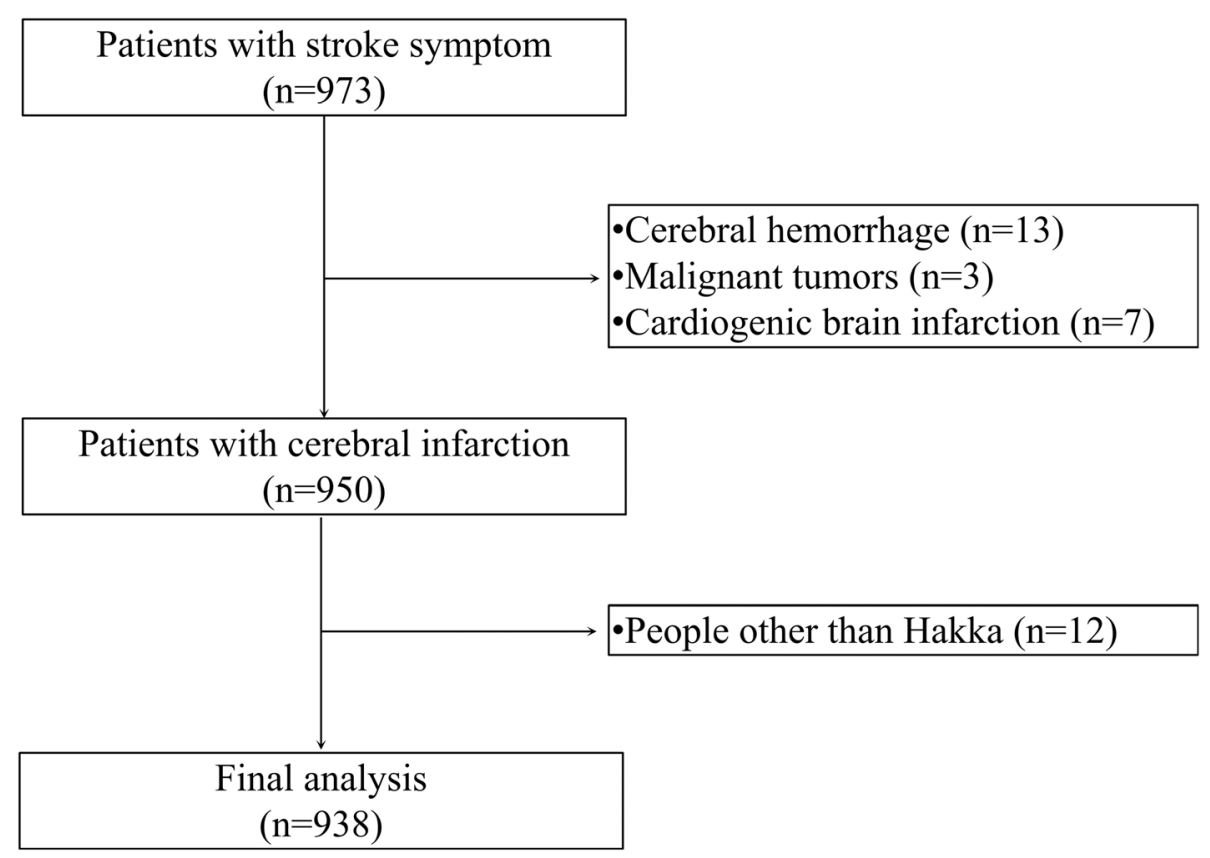

Fig. 1 Flow diagram of the study population recruitment process 


\section{Statistical analysis}

Data analysis was performed using SPSS statistical software version 21.0 (IBM Inc., State of New York, USA). Continuous variable data are represented by mean \pm standard deviation (SD), and categorical variables are represented by percentages. Student's $t$ test or the Mann-Whitney U test was used for continuous data analysis. Genotype composition ratios and allele frequencies between groups were analyzed by the chi-square test. Logistic regression analysis was applied to assess the interactions between SLCO1B1 and APOE polymorphisms and various factors (smoking, alcohol, hypertension, etc) in cerebral infarction. $P<0.05$ was considered statistically significant.

\section{Results}

\section{Population characteristics}

The 1966 individuals in this study, with ages between 20 and 99 years, consisted of $938 \mathrm{CI}$ patients (581 males and 357 females) and 1028 individuals with non-CI (622 males and 406 females) as controls. As shown in Table 1, the CI patients' average age was $65.6 \pm 10.6$ years, with $63.9 \pm 9.9$ years for males and $68.3 \pm 11.2$ years for females. The average age of the controls was $63.7 \pm 12.4$ years, with $62.9 \pm 12.6$ years and $64.8 \pm 12.1$ years for males and females, respectively. There were statistically significant differences in percentage of smokers $(P<$ $0.001)$, prevalence of hypertension $(P<0.001)$ and TG level $(P<0.001)$ between the patients and controls, though there were no statistically significant differences in age, TC, HDL-C, LDL-C, Apo-A1, Apo-B, Apo-A1/ Apo-B or percentage of alcohol cases. The differences in prevalence of hypertension $(P<0.001)$ and TG levels $(P=0.003)$ between female patients and female controls were also statistically significant, and prevalence of hypertension $(P<0.001)$ and TG levels $(P=0.009)$ were significant among males.

\section{Genotype and haplotype frequencies of $A P O E$ gene}

Among all subjects, the frequencies of genotypes $\varepsilon 3 / \varepsilon 3$, $\varepsilon 3 / \varepsilon 4, \varepsilon 2 / \varepsilon 3, \varepsilon 2 / \varepsilon 4, \varepsilon 4 / \varepsilon 4$, and $\varepsilon 2 / \varepsilon 2$ were $73.60,13.33$, $9.87,1.58,1.07$, and $0.56 \%$, respectively. The frequencies of alleles $\varepsilon 3, \varepsilon 4$ and $\varepsilon 2$ were $85.20,8.52$, and $6.28 \%$ respectively. The genotype distributions in both the CI patients and control participants were consistent with Hardy-Weinberg equilibrium $\left(X^{2}=4.495, P=0.488\right.$ and $X^{2}=1.855, P=0.879$, respectively). As the results showed, $\varepsilon 3 / \varepsilon 3$ was the most common APOE genotype, and $\varepsilon 3$ was the allele with the highest frequency, followed by $\varepsilon 4$ and $\varepsilon 2$ (Table 2).

There were statistically significant differences in genotype $\varepsilon 2 / \varepsilon 2\left(X^{2}=3.866, P=0.049\right), \varepsilon 2 / \varepsilon 3\left(X^{2}=20.030, P<\right.$ $0.001), \varepsilon 3 / \varepsilon 4\left(x^{2}=16.960, P<0.001\right)$, and $\varepsilon 4 / \varepsilon 4\left(X^{2}=\right.$ 4.786, $P=0.029)$ in the patients compared with the controls. The frequencies of genotypes $\varepsilon 2 / \varepsilon 3\left(\chi^{2}=14.579\right.$, $P<0.001)$ and $\varepsilon 3 / \varepsilon 4 \quad\left(X^{2}=15.177, P<0.001\right)$ between male patients and male controls showed statistically significant differences; in contrast, a significant difference only in genotype $\varepsilon 2 / \varepsilon 3\left(X^{2}=5.744, P=0.017\right)$ was detected among females (Patients vs Controls $=6.16 \%$ vs

Table 1 Clinical characteristics of males and females in cerebral infarction patients and control participants

\begin{tabular}{|c|c|c|c|c|c|c|c|c|c|}
\hline & \multicolumn{3}{|l|}{ Total $(n=1966)$} & \multicolumn{3}{|l|}{ Male $(n=1203)$} & \multicolumn{3}{|c|}{ Female $(n=763)$} \\
\hline & Patient Group & Control Group & $P$ values & Patient Group & Control Group & $P$ values & Patient Group & Control Group & $P$ values \\
\hline No. of subjects & 938 & 1028 & & 581 & 622 & & 357 & 406 & \\
\hline Age, y & $65.5 \pm 10.6$ & $63.7 \pm 12.4$ & 0.050 & $63.9 \pm 9.9$ & $62.9 \pm 12.6$ & 0.157 & $68.3 \pm 11.2$ & $64.8 \pm 12.1$ & $<0.001$ \\
\hline Smokers, n(\%) & $258(27.5 \%)$ & $224(21.8 \%)$ & 0.003 & $256(44.1 \%)$ & $224(36.0 \%)$ & 0.004 & $2(0.6 \%)$ & $0(0)$ & 0.219 \\
\hline Alcohol, n(\%) & $40(4.3 \%)$ & $39(3.8 \%)$ & 0.596 & $40(6.9 \%)$ & $39(6.3 \%)$ & 0.667 & $0(0)$ & $0(0)$ & - \\
\hline Hypertension, n(\%) & $663(70.7 \%)$ & 505 (49.1\%) & $<0.001$ & 406 (69.9\%) & 287 (46.1\%) & $<0.001$ & 257 (72.0\%) & $218(53.7 \%)$ & $<0.001$ \\
\hline $\mathrm{TG}, \mathrm{mmol} / \mathrm{L}$ & $2.145 \pm 2.388$ & $1.798 \pm 1.443$ & $<0.001$ & $2.128 \pm 2.560$ & $1.800 \pm 1.608$ & 0.009 & $2.171 \pm 2.101$ & $1.795 \pm 1.126$ & 0.003 \\
\hline $\mathrm{TC}, \mathrm{mmol} / \mathrm{L}$ & $5.114 \pm 1.398$ & $5.047 \pm 1.281$ & 0.268 & $4.967 \pm 1.280$ & $5.009 \pm 1.450$ & 0.595 & $5.276 \pm 1.299$ & $5.178 \pm 1.273$ & 0.294 \\
\hline $\mathrm{HDL}-\mathrm{C}, \mathrm{mmol} / \mathrm{L}$ & $1.279 \pm 0.373$ & $1.271 \pm 0.330$ & 0.623 & $1.231 \pm 0.358$ & $1.219 \pm 0.293$ & 0.533 & $1.355 \pm 0.368$ & $1.352 \pm 0.384$ & 0.907 \\
\hline LDL-C, mmol/L & $2.924 \pm 0.902$ & $2.864 \pm 0.948$ & 0.157 & $2.902 \pm 0.909$ & $2.836 \pm 0.957$ & 0.221 & $2.959 \pm 0.890$ & $2.908 \pm 0.935$ & 0.441 \\
\hline Apo-A1, g/L & $1.142 \pm 0.291$ & $1.153 \pm 0.333$ & 0.425 & $1.096 \pm 0.260$ & $1.098 \pm 0.299$ & 0.905 & $1.215 \pm 0.322$ & $1.237 \pm 0.364$ & 0.396 \\
\hline Apo-B, g/L & $0.904 \pm 0.266$ & $0.903 \pm 0.298$ & 0.909 & $0.899 \pm 0.268$ & $0.890 \pm 0.302$ & 0.582 & $0.912 \pm 0.264$ & $0.922 \pm 0.292$ & 0.631 \\
\hline Apo-A1/ Apo-B & $1.359 \pm 0.512$ & $1.404 \pm 0.611$ & 0.079 & $1.316 \pm 0.498$ & $1.370 \pm 0.626$ & 0.097 & $1.429 \pm 0.527$ & $1.455 \pm 0.584$ & 0.514 \\
\hline
\end{tabular}

Values for age expressed as mean \pm SD

TG triglycerides

$T C$ total cholesterol

$H D L-C$ high-density lipoprotein-cholesterol

$L D L-C$ low-density lipoprotein-cholesterol

Apo-A1 apolipoprotein $\mathrm{A} 1$

Apo-B apolipoprotein B 
Table 2 Genotypes and allele distribution of APOE gene in cerebral infarction patients and control participants in total and according to gender

\begin{tabular}{|c|c|c|c|c|c|c|}
\hline Genotypes & $\varepsilon 2 / \varepsilon 2$ & $\varepsilon 2 / \varepsilon 3$ & $\varepsilon 2 / \varepsilon 4$ & $\varepsilon 3 / \varepsilon 3$ & $\varepsilon 3 / \varepsilon 4$ & $\varepsilon 4 / \varepsilon 4$ \\
\hline All subjects & $11(0.56 \%)$ & 194 (9.87\%) & $31(1.58 \%)$ & $1447(73.60 \%)$ & $262(13.33 \%)$ & $21(1.07 \%)$ \\
\hline Patients $(n=938)$ & $2(0.21 \%)$ & $63(6.72 \%)$ & $18(1.92 \%)$ & $684(72.92 \%)$ & $156(16.63 \%)$ & $15(1.60 \%)$ \\
\hline Controls $(n=1028)$ & $9(0.88 \%)$ & $131(12.74 \%)$ & $13(1.26 \%)$ & $763(74.22 \%)$ & $106(10.31 \%)$ & $6(0.58 \%)$ \\
\hline$P$ values (Patients vs controls) & 0.049 & $<0.001$ & 0.279 & 0.513 & $<0.001$ & 0.029 \\
\hline \multicolumn{7}{|l|}{ Males } \\
\hline Patients $(n=581)$ & $2(0.34 \%)$ & $41(7.06 \%)$ & $16(2.75 \%)$ & 409 (70.40\%) & $104(17.90 \%)$ & $9(1.55 \%)$ \\
\hline Controls $(n=622)$ & $4(0.64 \%)$ & $86(13.83 \%)$ & $8(1.29 \%)$ & $458(73.63 \%)$ & $63(10.13 \%)$ & $3(0.48 \%)$ \\
\hline$P$ values (Patients vs controls) & - & $<0.001$ & 0.069 & 0.211 & $<0.001$ & - \\
\hline \multicolumn{7}{|l|}{ Females } \\
\hline Patients $(n=357)$ & $0(0)$ & $22(6.16 \%)$ & $2(0.56 \%)$ & $275(77.03 \%)$ & $52(14.57 \%)$ & $6(1.68 \%)$ \\
\hline Controls $(n=406)$ & $5(1.23 \%)$ & 45 (11.08\%) & $5(1.23 \%)$ & $305(75.12 \%)$ & $43(10.59 \%)$ & $3(0.74 \%)$ \\
\hline$P$ values (Patients vs controls) & - & 0.017 & 0.458 & 0.538 & 0.097 & - \\
\hline Alleles & $\varepsilon 2$ & $\varepsilon 3$ & $\varepsilon 4$ & & & \\
\hline All subjects $(n=3932)$ & $247(6.28 \%)$ & $3350(85.20 \%)$ & $335(8.52 \%)$ & & & \\
\hline Patients $(n=1876)$ & $85(4.53 \%)$ & 1587 (84.59\%) & $204(10.87 \%)$ & & & \\
\hline Controls $(n=2056)$ & $162(7.88 \%)$ & $1763(85.75 \%)$ & $131(6.37 \%)$ & & & \\
\hline$P$ values (Patients vs controls) & $<0.001$ & 0.309 & $<0.001$ & & & \\
\hline \multicolumn{7}{|l|}{ Males } \\
\hline Patients $(n=1162)$ & $61(5.25 \%)$ & $963(82.87 \%)$ & $138(11.88 \%)$ & & & \\
\hline Controls $(n=1244)$ & $102(8.20 \%)$ & $1065(85.61 \%)$ & 77 (6.19\%) & & & \\
\hline$P$ values (Patients vs controls) & 0.004 & 0.065 & $<0.001$ & & & \\
\hline \multicolumn{7}{|l|}{ Females } \\
\hline Patients $(n=714)$ & $24(3.36 \%)$ & $624(87.39 \%)$ & $66(9.24 \%)$ & & & \\
\hline Controls $(n=812)$ & $60(7.39 \%)$ & $698(85.96 \%)$ & $54(6.65 \%)$ & & & \\
\hline$P$ values (Patients vs controls) & 0.001 & 0.411 & 0.060 & & & \\
\hline
\end{tabular}

Numbers in parentheses are percentages

$11.08 \%)$. The frequencies of allele $\varepsilon 2\left(X^{2}=18.682, P<\right.$ $0.001)$ and $\varepsilon 4\left(X^{2}=25.516, P<0.001\right)$ showed statistically significant differences in the patients compared with controls, including between male patients and male controls and between female patients and female controls, respectively (Table 2 ).

\section{Genotype and haplotype frequencies of SLCO1B1 gene}

The frequencies of genotypes * $1 \mathrm{~b} /{ }^{*} 1 \mathrm{~b},{ }^{*} 1 \mathrm{a} /{ }^{*} 1 \mathrm{~b},{ }^{*} 1 \mathrm{~b} /{ }^{*} 15$, ${ }^{*} 1 \mathrm{a} /{ }^{*} 15$, ${ }^{*} 1 \mathrm{a} /{ }^{*} 1 \mathrm{a},{ }^{*} 15 /{ }^{*} 15$, and ${ }^{*} 1 \mathrm{a} /{ }^{*} 5$ were $41.40,32.50$, $13.48,5.95,5.44,1.17$, and $0.05 \%$, respectively, in all subjects. The corresponding frequencies in the CI patient group were $38.70,33.69,13.75,6.72,5.86,1.17$, and $0.11 \%$. And 43.87, 31.42, 13.23, 5.25, 5.06, 1.17, and $0 \%$ in the control group. The genotype distributions in both the CI patients and control participants were consistent with Hardy-Weinberg equilibrium $\left(\chi^{2}=1.661, P=0.962\right.$ and $\chi^{2}=0.514, P=0.992$, respectively). There was no statistically significant difference in the frequencies of these genotypes in the patients compared with the controls.
The frequencies of SLCO1B1 genotypes between male patients and male controls were not significantly different, nor were those in the female subjects (Table 3).

Four haplotypes of the two SNPs of SLCO1B1 were analyzed. The *1b (388G-521 T) haplotype (64.39\%) presented the highest frequency, followed by haplotype *1a (388A-521 T) (24.69\%), *15 (388G-521C) (10.89\%) and *5 (388A-521C) (0.03\%) haplotypes. The frequencies of SLCO1B1 haplotypes between male patients and male controls and between female patients and female controls showed no statistically significant differences (Table 3).

Relationships between serum lipid level and $A P O E$ allele and logistic regression analysis of the risk of $\varepsilon 4$ allele for $\mathrm{Cl}$

Relationships between $A P O E$ alleles ( $\varepsilon 2, \varepsilon 3$, and $\varepsilon 4)$ and serum lipid levels were analyzed. Subjects with the $A P O E \varepsilon 2 / \varepsilon 4$ genotype $(n=31)$ were excluded because $\varepsilon 2$ and $\varepsilon 4$ alleles play opposing roles in lipid metabolism. In 
Table 3 Genotypes and allele distribution of SLCO1B1 gene in cerebral infarction patients and control participants in total and according to gender

\begin{tabular}{|c|c|c|c|c|c|c|c|}
\hline Genotypes & $* 15 /{ }^{*} 15$ & ${ }^{*} 1 a /{ }^{*} 15$ & ${ }^{*} 1 a /{ }^{*} 1 a$ & ${ }^{*} 1 a /{ }^{*} 1 b$ & $* 1 a / * 5$ & $* 1 b / * 15$ & $* 1 b / * 1 b$ \\
\hline All subjects & $23(1.17 \%)$ & $117(5.95 \%)$ & $107(5.44 \%)$ & 639 (32.50\%) & $1(0.05 \%)$ & $265(13.48 \%)$ & $814(41.40 \%)$ \\
\hline Patients $(n=938)$ & $11(1.17 \%)$ & $63(6.72 \%)$ & $55(5.86 \%)$ & $316(33.69 \%)$ & $1(0.11 \%)$ & $129(13.75 \%)$ & $363(38.70 \%)$ \\
\hline Controls $(n=1028)$ & $12(1.17 \%)$ & $54(5.25 \%)$ & $52(5.06 \%)$ & $323(31.42 \%)$ & $0(0)$ & $136(13.23 \%)$ & $451(43.87 \%)$ \\
\hline$P$ values (Patients vs controls) & 0.991 & 0.171 & 0.432 & 0.283 & 0.477 & 0.734 & 0.020 \\
\hline \multicolumn{8}{|l|}{ Males } \\
\hline Patients $(n=581)$ & $8(1.38 \%)$ & $40(6.88 \%)$ & $35(6.02 \%)$ & 199 (34.25\%) & $1(0.17 \%)$ & $79(13.60 \%)$ & $219(37.69 \%)$ \\
\hline Controls $(n=622)$ & $11(1.77 \%)$ & $36(5.79 \%)$ & $35(5.63 \%)$ & $190(30.55 \%)$ & $0(0)$ & $85(13.67 \%)$ & $265(42.60 \%)$ \\
\hline$P$ values (Patients vs controls) & 0.586 & 0.435 & 0.769 & 0.170 & 0.483 & 0.972 & 0.083 \\
\hline \multicolumn{8}{|l|}{ Females } \\
\hline Patients $(n=357)$ & $3(0.84 \%)$ & $23(6.44 \%)$ & $20(5.60 \%)$ & 117 (32.77\%) & $0(0)$ & $50(14.01 \%)$ & $144(40.34 \%)$ \\
\hline Controls $(n=406)$ & $1(0.25 \%)$ & $18(4.43 \%)$ & 17 (4.19\%) & $133(32.76 \%)$ & $0(0)$ & $51(12.56 \%)$ & $186(45.81 \%)$ \\
\hline$P$ values (Patients vs controls) & - & 0.219 & 0.364 & 0.997 & - & 0.557 & 0.128 \\
\hline Alleles & $* 15$ & $* 5$ & $* 1 a$ & $* 1 b$ & & & \\
\hline All subjects $(n=3932)$ & $428(10.89 \%)$ & $1(0.03 \%)$ & $971(24.69 \%)$ & $2532(64.39 \%)$ & & & \\
\hline Patients $(n=1876)$ & $214(11.41 \%)$ & $1(0.05 \%)$ & $490(26.12 \%)$ & $1171(62.42 \%)$ & & & \\
\hline Controls $(n=2056)$ & $214(10.41 \%)$ & $0(0)$ & $481(23.39 \%)$ & $1361(66.20 \%)$ & & & \\
\hline$P$ values (Patients vs controls) & 0.315 & 0.477 & 0.048 & 0.014 & & & \\
\hline \multicolumn{8}{|l|}{ Males } \\
\hline Patients $(n=1162)$ & $135(11.62 \%)$ & $1(0.09 \%)$ & $310(26.68 \%)$ & $716(61.62 \%)$ & & & \\
\hline Controls $(n=1244)$ & $143(11.50 \%)$ & $0(0)$ & $296(23.79 \%)$ & $805(64.71 \%)$ & & & \\
\hline$P$ values (Patients vs controls) & 0.925 & 0.483 & 0.103 & 0.116 & & & \\
\hline \multicolumn{8}{|l|}{ Females } \\
\hline Patients $(n=714)$ & $79(11.06 \%)$ & $0(0)$ & $180(25.21 \%)$ & 455 (63.73\%) & & & \\
\hline Controls $(n=812)$ & $71(8.74 \%)$ & $0(0)$ & 185 (22.78\%) & $556(68.47 \%)$ & & & \\
\hline$P$ values (Patients vs controls) & 0.129 & - & 0.267 & 0.051 & & & \\
\hline
\end{tabular}

Numbers in parentheses are percentages

this study, $\varepsilon 4$ carriers had significantly higher LDL-C and Apo-B and lower Apo-A1/Apo-B levels than $\varepsilon 2$ and $\varepsilon 3$ carriers, but $\varepsilon 2$ carriers showed lower LDL-C and Apo-B and higher Apo-A1/Apo-B than $\varepsilon 3$ and $\varepsilon 4$ carriers. There were no significant impacts of $A P O E$ polymorphism on the TG, TC, HDL-C and Apo-A1 levels (Table 4).

Logistic regression analysis was performed to determine independent predictors for CI (Table 5), and the results indicated significantly higher risks of $\mathrm{CI}$ in the

Table 4 Relationships between serum lipid level and APOE allele in cerebral infarction patients and control participants

\begin{tabular}{|c|c|c|c|c|c|c|c|c|}
\hline \multirow{2}{*}{$\begin{array}{l}\text { Serum lipid } \\
\text { level }\end{array}$} & \multicolumn{4}{|c|}{ Cerebral infarction patients $(n=920)$} & \multicolumn{4}{|c|}{ Controls $(n=1015)$} \\
\hline & $\varepsilon 2(n=65)$ & $\varepsilon 3(n=684)$ & $\varepsilon 4(n=171)$ & $P$ values & $\varepsilon 2(n=140)$ & $\varepsilon 3(n=763)$ & $\varepsilon 4(n=112)$ & $P$ values \\
\hline $\mathrm{TG}, \mathrm{mmol} / \mathrm{L}$ & $2.064 \pm 1.986$ & $1.787 \pm 1.434$ & $1.773 \pm 1.285$ & 0.324 & $2.449 \pm 2.917^{*}$ & $2.069 \pm 2.208$ & $2.310 \pm 2.879$ & 0.170 \\
\hline $\mathrm{TC}, \mathrm{mmol} / \mathrm{L}$ & $4.893 \pm 1.245$ & $5.048 \pm 1.272$ & $5.093 \pm 1.320$ & 0.560 & $5.170 \pm 1.476$ & $5.096 \pm 1.351$ & $5.242 \pm 1.558$ & 0.534 \\
\hline $\mathrm{HDL}-\mathrm{C}, \mathrm{mmol} / \mathrm{L}$ & $1.302 \pm 0.336$ & $1.277 \pm 0.326$ & $1.234 \pm 0.336$ & 0.225 & $1.281 \pm 0.393$ & $1.284 \pm 0.367$ & $1.256 \pm 0.407$ & 0.762 \\
\hline $\mathrm{LDL}-\mathrm{C}, \mathrm{mmol} / \mathrm{L}$ & $2.584 \pm 0.766^{* \diamond}$ & $2.925 \pm 0.894$ & $3.031 \pm 0.922$ & 0.003 & $2.734 \pm 0.971^{*} \diamond$ & $2.866 \pm 0.917^{\diamond}$ & $3.061 \pm 1.064$ & 0.023 \\
\hline Apo-A1, g/L & $1.179 \pm 0.327$ & $1.150 \pm 0.284^{\diamond}$ & $1.098 \pm 0.307^{*}$ & 0.064 & $1.174 \pm 0.315$ & $1.161 \pm 0.344$ & $1.082 \pm 0.282$ & 0.050 \\
\hline Apo-B, g/L & $0.802 \pm 0.222^{* \diamond}$ & $0.905 \pm 0.263$ & $0.934 \pm 0.276$ & 0.002 & $0.858 \pm 0.312^{* \diamond}$ & $0.904 \pm 0.286^{\diamond}$ & $0.955 \pm 0.347$ & 0.035 \\
\hline Apo-A1/ Apo-B & $1.605 \pm 0.739^{* \diamond}$ & $1.366 \pm 0.501^{\diamond}$ & $1.244 \pm 0.409^{*}$ & $<0.001$ & $1.529 \pm 0.643^{* \diamond}$ & $1.401 \pm 0.616^{\diamond}$ & $1.260 \pm 0.506^{*}$ & 0.002 \\
\hline
\end{tabular}

$P$ value shows the differences compared between groups $(\varepsilon 2, \varepsilon 3, \varepsilon 4)$

${ }^{*} P<0.05$ versus corresponding $\varepsilon 3$ group

$\diamond_{P}<0.05$ versus corresponding $\varepsilon 4$ group 
presence of high LDL-C (OR 1.524, 95\% CI 1.092-2.100, $P=0.013$ ), and high ApoB (OR 3.046, 95\% CI 1.188$7.809, P=0.020$ ), smoking (OR 1.459 , 95\% CI $1.166-$ $1.825, P=0.001$ ), hypertension (OR 2.599, 95\% CI 2.136-3.164, $P<0.001$ ), and the $\varepsilon 4$ allele (OR 1.822, $95 \%$ CI 1.390-2.388, $P<0.001)$.

\section{Discussion}

Stroke is one of the most common causes of death and long-term disability worldwide [20]. Moreover, the stroke burden in China is expected to increase further due to an aging population and a continuing high prevalence of risk factors such as hyperlipidemia [21]. Cerebral infarction, the most common type of stroke, is known as localized brain tissue necrosis or cerebral ischemia caused by cerebral blood disorders, resulting from a blockage of the blood vessels that supply blood to the brain [22-25]. Many studies have shown that the etiology of cerebral infarction is complex, including genetic and environmental factors [26, 27]. The relationship between genetic polymorphisms of APOE and SLCO1B1 and $\mathrm{CI}$ were analyzed in this study.

The APOE gene encodes a major lipid-binding protein that serves as a cholesterol carrier [28]. Atherosclerosis is an important pathophysiological basis of CI. APOE gene polymorphisms have been shown to be associated with atherosclerosis $[29,30]$. However, the results of previous studies on the relationship between $A P O E$ gene polymorphisms and $\mathrm{CI}$ are not very consistent. For example, Yan et al. [31] indicated that the $\varepsilon 4$ allele was associated with TC and LDL-C and believed that $\varepsilon 4$ was a genetic marker of CI. Liu et al. [32] confirmed by MRI scanning that brain injury was aggravated in $\varepsilon 4$ allele carriers CI patients after stroke. However, Wang et al. [33] proposed that $A P O E$ gene polymorphism did not correlate significantly with CI. Based on the results of the present study, there were statistically significant differences in genotypes $\varepsilon 2 / \varepsilon 2, \varepsilon 2 / \varepsilon 3, \varepsilon 3 / \varepsilon 4$, and $\varepsilon 4 / \varepsilon 4$ among CI patients compared with controls. $\varepsilon 4$ carriers had significantly higher LDL-C and Apo-B and lower Apo-A1/Apo-B levels than the other groups, while $\varepsilon 2$ carriers showed lower LDL-C and Apo-B and higher Apo-A1/Apo-B. Logistic regression analysis indicated

Table 5 Logistic regression analysis of risks of cerebral infarction in southern Chinese Hakka population

\begin{tabular}{llll}
\hline Variables & $\beta$ & $P$ value & Adjusted OR $(95 \% \mathrm{Cl})$ \\
\hline LDL-C & 0.415 & 0.013 & $1.092-2.100$ \\
ApoB & 1.114 & 0.020 & $1.188-7.809$ \\
Smoking & 0.378 & 0.001 & $1.166-1.825$ \\
Hypertension & 0.955 & $<0.001$ & $2.136-3.164$ \\
$\varepsilon 4$ carrier & 0.600 & $<0.001$ & $1.390-2.388$ \\
\hline
\end{tabular}

$O R$ odds ratio, $C l$ confidence interval, $L D L-C$ low-density lipoprotein-cholesterol that participants with $\varepsilon 4$ allele had a significantly higher risk of $\mathrm{CI}$.

$A P O E$ gene polymorphisms are important determinants of blood lipid levels, and it may be the reason for the correlation between $A P O E$ gene polymorphisms and CI [34]. The APOE \&4 allele is associated with higher serum lipid levels, whereas the $\varepsilon 2$ allele is associated with the lower levels [35]. In addition, the presence of $\varepsilon 2$ has been associated with lower LDL-C level but with no influence on HDL-C level [34]. Another study showed that the C allele of SNP rs2910164 of the miR-146a gene is a risk factor for atherosclerotic cerebral infarction (ACI) and that $A P O E \& 4$ may enhance $\mathrm{ACI}$ susceptibility by reducing miR-146a expression [36].

Furthermore, this study found $\varepsilon 3$ to be the most common allele of the APOE gene, accounting for $85.20 \%$, which was consistent with most previous studies [37, 38]. This indicates that the $A P O E$ allele frequencies in the Meizhou area are similar to those of the ChineseNortheast [39], Chinese-Jiangsu Han [40] and ChineseKunming Han [41] areas, though the $\varepsilon 4$ allele frequency in Meizhou is lower than that in Shanghai [42].

The frequencies of SLCO1B1 genotypes "1b/*1b, "1a/ "1b, " $1 \mathrm{~b} /{ }^{*} 15,{ }^{*} 1 \mathrm{a} /{ }^{*} 15,{ }^{*} 1 \mathrm{a} /{ }^{*} 1 \mathrm{a},{ }^{*} 15 /{ }^{*} 15$, and $" 1 \mathrm{a} /{ }^{*} 5$ were $41.10,32.79,13.03,5.93,5.88,1.22$, and $0.05 \%$ respectively. The frequency of $S L C O 1 B 1$ haplotype *1b revealed its predominance, accounting for $64.01 \%$, followed by "1a (25.27\%), "15 (10.69\%) and "5 (0.03\%). These results are in agreement with previous studies [43-46]. Greek, German, Indian (North) and Macedonian populations exhibit relatively lower rates of " $1 \mathrm{~b}$ (less than 50\%), whereas Thailand and Chinese populations show higher rates, generally above $60-70 \%$. In contrast, the allele frequency of haplotypes *15 and "5 displayed little difference. In this study, there were no statistically significant differences in the frequencies of SLCO1B1 genotypes and haplotypes between CI patients and control participants. In addition, no information has been published about relationship between cerebral infarction and SLCO1B1 gene polymorphisms in other populations.

\section{Study strengths and limitations}

There are several strengths of this study. This is the first study about the relationship of cerebral infarction and SLCO1B1 gene polymorphism. The clinical characteristics, lipid levels and $A P O E$ gene polymorphism indicators were included into the analysis to exclude the influence of related confounding factors on the results. There are some limitations to this study that should be noted. First, $\mathrm{CI}$ is a kind of multifactorial diseases caused by genetic and environmental factors. As a retrospective case control analysis, the limitations of the original data included in this study constrained assessment of potential gene-environment interactions. Second, the sample 
size of this study is not very large, which may lead to some deviations in the results. Therefore, further study with a larger sample size is one of the next tasks. Third, the study was carried out only in Hakka Chinese people, and whether the same is true for other populations needs further investigation.

\section{Conclusions}

In conclusion, the present study suggests that the SNPs rs429358 and rs7412 of the APOE gene but not SNPs rs 2306283 and rs4149056 of the SLCO1B1 gene are associated with ischemic cerebral infarction in the southern Chinese Hakka population. Therefore, APOE genotyping may be useful to identify individuals at risk of $\mathrm{CI}$ and provide guidance for the institution of individualized preventive strategies and therapies for patients.

\section{Abbreviations}

APOE: apolipoprotein E; SLCO1B1: solute carrier organic anion transporter family member 1B1; TG: triglycerides; TC: total cholesterol; HDL-C: highdensity lipoprotein-cholesterol; LDL-C: low-density lipoprotein-cholesterol; Apo-A1: apolipoprotein A1; Apo-B: apolipoprotein B

\section{Acknowledgements}

The author would like to thank other colleagues whom were not listed in the authorship of Center for Precision Medicine, Meizhou People's Hospital (Huangtang Hospital), Meizhou Academy of Medical Sciences, Meizhou Hospital Affiliated to Sun Yat-sen University for their helpful comments on the manuscript.

\section{Authors' contributions}

Zhixiong Zhong and Heming Wu designed the study. Heming Wu, Qingyan Huang and Hailing Wu collected clinical data. Heming Wu, Qingyan Huang and Zhikang Yu analyzed the data. Heming Wu prepared the manuscript. All authors were responsible for critical revisions, and all authors read and approved the final version of this work

\section{Funding}

This study was supported by Key Scientific and Technological Project of Meizhou People's Hospital, (Grant No.: MPHKSTP-20180101 to Dr. Zhixiong Zhong) and the Guangdong Provincial Key Laboratory of Precision Medicine and Clinical Translation Research of Hakka Population (Grant No.:

2018B030322003), the Science and Technology Program of Meizhou (Grant No. 2019B0202001).

\section{Availability of data and materials}

All data generated or analyzed during this study are included in this published article.

\section{Ethics approval and consent to participate}

The study was approved by the Ethics Committee of Medicine, Meizhou People's Hospital (Huangtang Hospital), Meizhou Academy of Medical Sciences, Meizhou Hospital Affiliated to Sun Yat-sen University.

\section{Consent for publication}

Not applicable.

\section{Competing interests}

The authors declare that they have no competing interests.

\section{Author details}

${ }^{1}$ Center for Precision Medicine, Meizhou People's Hospital (Huangtang Hospital), Meizhou Academy of Medical Sciences, Meizhou Hospital Affiliated to Sun Yat-sen University, Meizhou, P. R. China. ${ }^{2}$ Guangdong Provincial Key Laboratory of Precision Medicine and Clinical Translational Research of Hakka Population, Meizhou People's Hospital (Huangtang Hospital), Meizhou
Academy of Medical Sciences, Meizhou Hospital Affiliated to Sun Yat-sen University, Meizhou, P. R. China. ${ }^{3}$ Guangdong Provincial Engineering and Technology Research Center for Clinical Molecular Diagnostics and Antibody Therapeutics, Meizhou People's Hospital (Huangtang Hospital), Meizhou Academy of Medical Sciences, Meizhou Hospital Affiliated to Sun Yat-sen University, Meizhou, P. R. China. ${ }^{4}$ Guangdong Provincial Engineering and Technology Research Center for Molecular Diagnostics of Cardiovascular Diseases, Meizhou People's Hospital (Huangtang Hospital), Meizhou Academy of Medical Sciences, Meizhou Hospital Affiliated to Sun Yat-sen University, Meizhou, P. R. China. ${ }^{5}$ Center for Cardiovascular Diseases, Meizhou People's Hospital (Huangtang Hospital), Meizhou Academy of Medical Sciences, Meizhou Hospital Affiliated to Sun Yat-sen University, Meizhou, P. R. China.

Received: 24 June 2020 Accepted: 26 August 2020

Published online: 05 September 2020

\section{References}

1. Wang Y, Cui L, Ji X, Dong Q, Zeng J, Wang Y, Zhou Y, Zhao X, Wang C, Liu $L$, et al. The China National Stroke Registry for patients with acute cerebrovascular events: design, rationale, and baseline patient characteristics. Int J Stroke. 2011;6:355-61.

2. Han YH. Association between IL6 polymorphism and risk of cerebral infarction. Genet Mol Res. 2015;14:16438-43.

3. Cheng SY, Zhao YD, Zeng JW, Chen XY, Wang RD. A polymorphism $(-455 \mathrm{G}>\mathrm{a})$ in the $\beta$-fibrinogen gene is associated with an increased risk of cerebral infarction in the Chinese population: a meta-analysis. J ReninAngiotensin-Aldosterone Syst. 2015;16:399-408.

4. Xiao J, Li X, Yuan Q, Zhang S, Qu K, Wu B, Wang Y, Duan S. PON1 Hypermethylation and PON3 Hypomethylation are associated with risk of cerebral infarction. Curr Neurovasc Res. 2019;16:115-22.

5. Zhang SY, Xu ML, Zhang CE, Qu ZY, Zhang BB, Zheng ZY, Zhang LM. Association of ALOX5AP gene single nucleotide polymorphisms and cerebral infarction in the Han population of northern China. BMC Med Genet. 2012;13:61

6. Moon KS, Lee HJ, Hong SH, Kim HM, Um JY. CYP1A1 and GSTM1/T1 genetic variation in predicting risk for cerebral infarction. J Mol Neurosci. 2007;32: $155-9$.

7. Zeng TT, Tang DJ, Ye YX, Su J, Jiang H. Influence of SCARB1 gene SNPS on serum lipid levels and susceptibility to coronary heart disease and cerebral infarction in a Chinese population. Gene. 2017;626:319-25.

8. Zhong Z, Wu H, Ye M, Yang Y, Luo W, Wu Y, Wu H, Zhong M, Zhao P. Association of APOE gene polymorphisms with cerebral infarction in the Chinese population. Med Sci Monit. 2018;24:1171-7.

9. Yan HC, Wang W, Dou CW, Tian FM, Qi ST. Relationships of LDLR genetic polymorphisms with cerebral infarction: a meta-analysis. Mol Biol Rep. 2014; 41:4425-34.

10. Yamaguchi S, Yamada Y, Metoki N, Yoshida H, Satoh K, Ichihara S, Kato K, Kameyama T, Yokoi K, Matsuo $H_{\text {, }}$ et al. Genetic risk for atherothrombotic cerebral infarction in individuals stratified by sex or conventional risk factors for atherosclerosis. Int J Mol Med. 2006;18:871-83.

11. Seripa D, D'Onofrio G, Panza F, Cascavilla L, Masullo C, Pilotto A. The genetics of the human APOE polymorphism. Rejuvenation Res. 2011;14:491-500.

12. Zintzaras E, Kitsios GD, Triposkiadis F, Lau J, Raman G. APOE gene polymorphisms and response to statin therapy. Pharmacogenomics J. 2009; 9:248-57.

13. Nies AT, Niemi M, Burk O, Winter S, Zanger UM, Stieger B, Schwab M, Schaeffeler E. Genetics is a major determinant of expression of the human hepatic uptake transporter OATP1B1, but not of OATP1B3 and OATP2B1. Genome Med. 2013:5:1

14. Kalliokoski A, Niemi M. Impact of OATP transporters on pharmacokinetics. Br J Pharmacol. 2009:158:693-705.

15. Kameyama Y, Yamashita K, Kobayashi K, Hosokawa M, Chiba K. Functional characterization of SLCO1B1 (OATP-C) variants, SLCO1B1*5, SLCO1B1*15 and SLCO1B1*15+C1007G, by using transient expression systems of HeLa and HEK293 cells. Pharmacogenet Genomics. 2005;15:513-22.

16. Tirona RG, Leake BF, Wolkoff AW, Kim RB. Human organic anion transporting polypeptide-C (SLC21A6) is a major determinant of rifampinmediated pregnane $X$ receptor activation. J Pharmacol Exp Ther. 2003;304: 223-8.

17. Nozawa T, Minami H, Sugiura S, Tsuji A, Tamai I. Role of organic anion transporter OATP1B1 (OATP-C) in hepatic uptake of irinotecan and its active 
metabolite, 7-ethyl-10-hydroxycamptothecin: in vitro evidence and effect of single nucleotide polymorphisms. Drug Metab Dispos. 2005;33:434-9.

18. Luo JQ, He FZ, Wang ZM, Sun NL, Wang LY, Tang GF, Liu MZ, Li Q, Chen XP, Liu ZQ, et al. SLCO1B1 variants and angiotensin converting enzyme inhibitor (Enalapril)-induced cough: a Pharmacogenetic study. Sci Rep. 2015;5:17253.

19. Belderbos BPS, de With M, Singh RK, Agema BC, El Bouazzaoui S, Oomen-de Hoop E, de Wit R, van Schaik RHN, Mathijssen RHJ, Bins S. The influence of single-nucleotide polymorphisms on overall survival and toxicity in cabazitaxel-treated patients with metastatic castration-resistant prostate cancer. Cancer Chemother Pharmacol. 2020;85:547-53.

20. Donnan GA, Fisher M, Macleod M, Davis SM. Stroke. Lancet. 2008;371:1612-23.

21. Wu S, Wu B, Liu M, Chen Z, Wang W, Anderson CS, Sandercock P, Wang Y, Huang Y, Cui L, et al. Stroke in China: advances and challenges in epidemiology, prevention, and management. Lancet Neurol. 2019;18:394-405.

22. Brott T, Adams HP Jr, Olinger CP, Marler JR, Barsan WG, Biller J, Spilker J, Holleran R, Eberle R, Hertzberg V, et al. Measurements of acute cerebral infarction: a clinical examination scale. Stroke. 1989:20:864-70

23. Fletcher AP, Alkjaersig N, Lewis M, Tulevski V, Davies A, Brooks JE, Hardin WB, Landau WM, Raichle ME. A pilot study of urokinase therapy in cerebral infarction. Stroke. 1976;7:135-42.

24. Hofmeijer J, Kappelle LJ, Algra A, Amelink GJ, van Gijn J, van der Worp HB. Surgical decompression for space-occupying cerebral infarction (the Hemicraniectomy after middle cerebral artery infarction with lifethreatening edema trial [HAMLET]): a multicentre, open, randomised trial. Lancet Neurol. 2009;8:326-33.

25. Liu M, Wu B, Wang WZ, Lee LM, Zhang SH, Kong LZ. Stroke in China: epidemiology, prevention, and management strategies. Lancet Neurol. 2007; 6:456-64.

26. Meschia JF, Worrall BB, Rich SS. Genetic susceptibility to ischemic stroke. Nat Rev Neurol. 2011:7:369-78.

27. Flossmann E, Schulz UG, Rothwell PM. Systematic review of methods and results of studies of the genetic epidemiology of ischemic stroke. Stroke. 2004;35:212-27.

28. Mahley RW. Apolipoprotein E: cholesterol transport protein with expanding role in cell biology. Science. 1988;240:622-30.

29. Gungor Z, Anuurad E, Enkhmaa B, Zhang W, Kim K, Berglund L. Apo E4 and lipoprotein-associated phospholipase A2 synergistically increase cardiovascular risk. Atherosclerosis. 2012;223:230-4.

30. Shakhtshneider EV, Ragino YI, Chernjavski AM, Kulikov IV, Ivanova MV, Voevoda MI. Apolipoprotein E gene polymorphism in men with coronary atherosclerosis in Siberia. Bull Exp Biol Med. 2011;150:355-8,

31. Yan S, Zhou X, Li X, Yu D, Ha D. Relationsbip between gene polymorphism of apolipoprotein $E$ and serum lipids, lipoproteins, and apolipoproteins in Chinese patients with atherothrombotic brain infarction. Chin J Neuroimmunlolgy Neurol. 1997;4:16-21.

32. Liu Y, Laakso MP, Karonen JO, Vanninen RL, Nuutinen J, Soimakallio S, Aronen HJ. Apolipoprotein E polymorphism and acute ischemic stroke: a diffusion- and perfusion-weighted magnetic resonance imaging study. J Cereb Blood Flow Metab. 2002;22:1336-42.

33. Wang T, He Z, Li Y, Liu F, Huang S, Zhou T. The relation between apolipoprotein E gene polymorphism and atherosclerotic cerebra infarction. Yi Chuan. 2000;22:4-6.

34. Pablos-Méndez A, Mayeux R, Ngai C, Shea S, Berglund L. Association of apo E polymorphism with plasma lipid levels in a multiethnic elderly population. Arterioscler Thromb Vasc Biol. 1997;17:3534-41.

35. Mahley RW, Rall SC Jr. Apolipoprotein E: far more than a lipid transport protein. Annu Rev Genomics Hum Genet. 2000;1:507-37.

36. Zhong H, Cai Y, Cheng J, Cai D, Chen L, Su C, Li K, Chen P, Xu J, Cui L. Apolipoprotein E epsilon 4 enhances the association between the rs2910164 polymorphism of miR-146a and risk of atherosclerotic cerebral infarction. J Atheroscler Thromb. 2016;23:819-29.

37. Marais AD. Apolipoprotein E in lipoprotein metabolism, health and cardiovascular disease. Pathology. 2019;51:165-76.

38. Griffin B, Walker C, Jebb S, Moore C, Frost G, Goff L, Sanders T, Lewis F, Griffin M, Gitau R. APOE4 genotype exerts greater benefit in lowering plasma cholesterol and apolipoprotein B than wild type (E3/E3), after replacement of dietary saturated fats with low glycaemic index carbohydrates. Nutrients. 2018;10:1524.

39. Zhou J, Xue YL, Guan YX, Yang YD, Fu SB, Zhang JC. Association study of apolipoprotein e gene polymorphism and cerebral infarction in type 2 diabetic patients. Yi Chuan. 2005;27:35-8.
40. Liang S, Pan M, Geng HH, Chen H, Gu LQ, Qin XT, Qian JJ, Zhu JH, Liu CF. Apolipoprotein E polymorphism in normal Han Chinese population: frequency and effect on lipid parameters. Mol Biol Rep. 2009;36:1251-6.

41. Tang H, Yan X, Hua Y, Wei M, Zhang L, Gao J, Dong H. Distribution of apoE polymorphism in Chinese Yunnan Dehong Dai ethnic group. Zhonghua Yi Xue Yi Chuan Xue Za Zhi. 2005;22:224-6.

42. Yang JD, Feng GY, Zhang J, Cheung J, St Clair D, He L, Ichimura K. Apolipoprotein E-491 promoter polymorphism is an independent risk factor for Alzheimer's disease in the Chinese population. Neurosci Lett. 2003;350:25-8.

43. Mladenovska K, Grapci AD, Vavlukis M, Kapedanovska A, Eftimov A, Geshkovska NM, Nebija D, Dimovski AJ. Influence of SLCO1B1 polymorphisms on atorvastatin efficacy and safety in Macedonian subjects. Pharmazie. 2017;72:288-95

44. Hubacek JA, Dlouha D, Adamkova V, Zlatohlavek L, Viklicky O, Hruba P, Ceska R, Vrablik M. SLCO1B1 polymorphism is not associated with risk of statin-induced myalgia/myopathy in a Czech population. Med Sci Monit. 2015;21:1454-9.

45. Melo MS, Balanco L, Branco CC, Mota-Vieira L. Genetic variation in key genes associated with statin therapy in the Azores Islands (Portugal) healthy population. Ann Hum Biol. 2015;42:283-9.

46. Wu X, Gong C, Weinstock J, Cheng J, Hu S, Venners SA, Hsu YH, Wu S, Zha $X$, Jiang $S$, et al. Associations of the SLCO1B1 polymorphisms With hepatic function, baseline lipid levels, and lipid-lowering response to simvastatin in patients With hyperlipidemia. Clin Appl Thromb Hemost. 2018; 1076029618805863

\section{Publisher's Note}

Springer Nature remains neutral with regard to jurisdictional claims in published maps and institutional affiliations.

Ready to submit your research? Choose BMC and benefit from:

- fast, convenient online submission

- thorough peer review by experienced researchers in your field

- rapid publication on acceptance

- support for research data, including large and complex data types

- gold Open Access which fosters wider collaboration and increased citations

- maximum visibility for your research: over $100 \mathrm{M}$ website views per year

At $\mathrm{BMC}$, research is always in progress.

Learn more biomedcentral.com/submissions 